\title{
Lipopolysaccharide-stimulated Osteoclastogenesis Is Mediated by Tumor Necrosis Factor Via its P55 Receptor
}

\author{
Yousef Abu-Amer, F. Patrick Ross, Jennifer Edwards, and Steven L. Teitelbaum \\ Department of Pathology, Washington University School of Medicine, St. Louis, Missouri 63110
}

\begin{abstract}
Chronic bone infection, as attends periodontitis, is often complicated by severe osteolysis. While LPS is believed to be central to the pathogenesis of the osteolytic lesion, the mechanisms by which this bacteria-derived molecule promotes bone resorption are unknown. We find that LPS induces bone marrow macrophages (BMMs) to express c-src, a protooncogene product that we demonstrate is a specific marker of commitment to the osteoclast phenotype. We next turned to possible soluble mediators of LPS-induced c-src. Of a number of osteoclastogenic cytokines tested, only TNF- $\alpha$ mirrors the c-src-enhancing effect of LPS. Suggesting that LPS augmentation of c-src is TNF-mediated, endotoxin sequentially induces BMM expression of TNF, followed by c-src. TNF and c-src expression, by cultured BMMs derived from LPS-injected mice, reflects duration of exposure to circulating endotoxin, intimating that endotoxin's effect in vivo is also mediated by TNF. Consistent with these findings, thalidomide (which antagonizes TNF action) attenuates c-src induction by LPS. An anti-TNF antibody blocks LPS enhancement of c-src mRNA, validating the cytokine's modulating role in vitro. Using BMMs of TNF receptor-deleted mice, we demonstrate that TNF induction of c-src is transmitted through the cytokine's p55, but not p75, receptor. Most importantly, LPS administered to wild-type mice prompts osteoclast precursor differentiation, manifest by profound osteoclastogenesis in marrow cultured ex vivo, and by a profusion of marrow-residing cells expressing the osteoclast marker tartrate resistant acid phosphatase, in vivo. In contrast, LPS does not substantially enhance osteoclast proliferation in mice lacking the p55TNF receptor, confirming that LPS-induced osteoclastogenesis is mediated by TNF in vivo via this receptor. Thus, therapy targeting TNF and/or its p55 receptor presents itself as a means of preventing the osteolysis of chronic bacterial infection. (J. Clin. Invest. 1997. 100:1557-1565.) Key words: bone resorption - periodontitis - tumor necrosis factor receptor $\bullet$ thalidomide $\bullet$ bone marrow macrophages
\end{abstract}

Address correspondence to Steven L. Teitelbaum, M.D., Department of Pathology, Washington University School of Medicine, BarnesJewish Hospital North, 216 South Kings Highway, St. Louis, MO 63110. Phone: 314-454-8463; FAX: 314-454-5505; E-mail: teitelbs@ medicine.wustl.edu

Received for publication 27 April 1997 and accepted in revised form 24 June 1997.

J. Clin. Invest.

(C) The American Society for Clinical Investigation, Inc. 0021-9738/97/09/1557/09 \$2.00

Volume 100, Number 6, September 1997, 1557-1565

http://www.jci.org

\section{Introduction}

Chronic infection of bone or periosseous tissues by gram-negative bacteria, as occurs in disorders such as periodontal disease $(1,2)$ and otitis media $(3)$, respectively, are attended by osteolysis. In fact, the alveolar bone loss complicating periodontitis is probably the most common form of clinically significant osteopenia occurring in man (2).

It is now clear that bone loss accompanying chronic infection reflects enhanced osteoclastic activity (2). In fact, the most reasonable paradigm holds that the products of gram-negative bacteria in some manner induce osteoclastic bone resorption (2). Thus, understanding the means by which bacterial components enhance resorption would provide a therapeutic strategy to prevent this family of osteopenic disorders.

While other bacterial products may be involved, LPS appears to be the major mediator of the bone loss accompanying chronic infection (2). Not only is LPS abundant in foci of periodontal disease $(4,5)$, but the molecule is known to stimulate bone resorption when added to organ culture (6). The mechanisms by which LPS activates the resorptive process are, however, unknown (2). Specifically, there is little information as to whether endotoxin enhances osteoclastogenesis by directly targeting osteoclast precursors, or indirectly, via intermediary cells such as osteoblasts. Of even more profound therapeutic potential, it is unknown if LPS per se is resorptive or if its osteolytic properties are mediated by one or more of the many cytokines induced by the bacterial product (2).

We have explored the osteoclastogenic mechanisms of LPS using a variety of in vitro and in vivo models of osteoclast differentiation. We find that endotoxin directly targets osteoclast precursors in the form of pure populations of murine bone marrow macrophages (BMMs) ${ }^{1}$, prompting their commitment to the osteoclast phenotype, manifest by expression of the osteoclast-specific protein, c-src. The c-src-inductive effect of LPS is mediated by TNF- $\alpha$ and is transmitted through the cytokine's p55 receptor. Most importantly, these in vitro observations are extant in respect to LPS-induced osteoclastogenesis in vivo, which we demonstrate is blunted in mice devoid of the p55 TNF receptor (TNFr). Thus, therapy targeted to TNF or its p55 receptor, presents itself as a means of preventing osteolysis of chronic infection.

\section{Methods}

Reagents. Monoclonal antibody 327 (7), directed against the c-src protein, full-length c-src cDNA was a gift of Dr. A. Shaw (Department of Pathology, Washington University School of Medicine, St. Louis, MO). All cytokines as well as monoclonal and polyclonal antiTNF antibodies were purchased from Genzyme Corp. (Cambridge,

1. Abbreviations used in this paper: BMM, bone marrow macrophages; RT, room temperature; TNFr, TNF receptor; TRAP, tartate-resistant acid phosphatase. 
MA). $1,25(\mathrm{OH})_{2} \mathrm{D}_{3}$ was a gift of Dr. Milan Uskokovic (Hoffmann LaRoche, Nutley, NJ). Thalidomide was kindly provided by Dr. R. Stites (Pediatric Pharmaceuticals, Westfield, NJ). ECL kit was obtained from Amersham Corp. (Arlington Heights, IL). All other chemicals were obtained from Sigma Chemical Co. (St. Louis, MO).

Mice. $\mathrm{C} 3 \mathrm{H} / \mathrm{HeN}$ male mice (Harlan Sprague Dawley Inc., Indianapolis, IN) were used. Transgenic mice include: (a) mice in which the p55TNF receptor gene has been deleted (8) (provided by Dr. Warner Lesslauer [Hoffman-LaRoche]); $(b)$ those in which the p75TNF receptor gene has been deleted (9); (c) those in which both the p55 and p75TNF receptor genes have been deleted by interbreeding dominant negative p55TNF receptor knockout mice with their counterparts from p75TNF receptor knockout mice (provided by Dr. Mark Moore [Genentech Inc., South San Francisco, CA]), and (d) their respective wild-type mice.

Cell culture. BMMs were isolated from whole bone marrow of 4-6-wk-old mice, and were incubated in tissue culture plates at $37^{\circ} \mathrm{C}$ in $5 \% \mathrm{CO}_{2}$ in the presence of CSF-1 $(1,000 \mathrm{U} / \mathrm{ml})(10)$. After $24 \mathrm{~h}$ in culture, the nonadherent cells were collected and layered on a FicollHypaque gradient, and the cells at the gradient interface were collected and plated in $\alpha$-MEM, supplemented with $10 \%$ heat-inactivated $\mathrm{FBS}$, at $37^{\circ} \mathrm{C}$ in $5 \% \mathrm{CO}_{2}$ in the presence of CSF-1 $(1,000 \mathrm{U} / \mathrm{ml})$, and plated according to each experimental condition. Osteoclastogenic cultures were obtained using two different protocols: $(a)$ whole bone marrow cells, which differentiate in vitro into osteoclast-like cells, were isolated from the tibia and femurs of 4-6-wk-old mice (cells were plated at a density of $5 \times 10^{6} / \mathrm{cm}^{2} / \mathrm{ml}$, and were maintained for $7 \mathrm{~d}$ in the presence of $10 \mathrm{nM} 1,25(\mathrm{OH})_{2} \mathrm{D}_{3}$ and $100 \mathrm{nM}$ dexamethasone, at $37^{\circ} \mathrm{C}$ in $5 \% \mathrm{CO}_{2}(11)$; and $(b)$ pure BMMs were cultured with ST2 cells at density of $10^{5}$ cells $/ 1 \mathrm{~cm}^{2} / 1 \mathrm{ml}$ (ratio 10:1) in the presence of $10 \mathrm{nM} 1,25(\mathrm{OH})_{2} \mathrm{D}_{3}$ and $100 \mathrm{nM}$ dexamethasone (12). Cocultured cells were supplemented with fresh media and steroids on the fourth day. A typical monolayer of multinucleated osteoclasts was obtained between culture days seven and nine. ST2 cells were collagenase-removed (13), and remaining osteoclasts and their precursors were used according to the experimental conditions.

Immunoprecipitation. Adherent cells were scraped from the dish in the presence of lysis buffer $(10 \mathrm{mM}$ Tris, $150 \mathrm{mM} \mathrm{NaCl}, 1 \mathrm{mM}$ $\mathrm{CaCl}_{2}, 1 \%$ deoxycholic acid, $1 \%$ Triton $\mathrm{X}-100,0.02 \% \mathrm{NaN}_{3}, 10 \mu \mathrm{g} / \mathrm{ml}$ aprotinin, $1 \mathrm{mM}$ AEBSF, $\mathrm{pH} 7.8$ ), and incubated at $4^{\circ} \mathrm{C}$ with gentle rocking for $30 \mathrm{~min}$. The cells were then passed through a 25 -gauge needle and spun at $10,000 \mathrm{rpm}$ for $10 \mathrm{~min}$ in a microfuge. Lysates were precleared with excess of protein A-sepharose (Sigma Chemical Co.) and protein G-sepharose (Pharmacia LKB Biotechnology Inc., Piscataway, NJ). Cleared lysates were incubated with various antibodies followed by protein $\mathrm{A}$ or $\mathrm{G}$ beads, as indicated in each experiment, and the beads containing immune complexes were washed extensively with lysis buffer.

Immunoblotting. Immunoprecipitated proteins or total cell lysates were boiled in the presence of SDS-sample buffer $(0.5 \mathrm{M}$ Tris- $\mathrm{HCl}, \mathrm{pH} 6.8,10 \%$ [wt/vol] SDS, $10 \%$ glycerol, $0.05 \%$ [wt/vol] bromophenol blue, distilled water) for $5 \mathrm{~min}$, and subjected to electrophoresis on $8 \%$ SDS-PAGE (14). Proteins were transferred to nitrocellulose membranes using a semidry blotter (Bio-Rad Laboratories, Richmond, CA) and incubated in blocking solution (10\% skim milk prepared in PBS containing $0.05 \%$ Tween-20), to reduce nonspecific binding. Membranes were washed with PBS/Tween buffer and exposed to primary antibodies ( $1 \mathrm{~h}$ at room temperature [RT] up to overnight at $4^{\circ} \mathrm{C}$ ), washed again four times, and incubated with secondary goat anti-mouse HRP-conjugated antibody ( $1 \mathrm{~h}, \mathrm{RT})$. Membranes were washed extensively $(5 \times 15 \mathrm{~min})$, and an ECL detection assay was performed following the manufacturer's directions.

RNA extraction and Northern analysis. Mouse bone marrow macrophages were washed three times with PBS, and total RNA was isolated using RNAzol blue reagent (Tel-Test Inc., Friendswood, TX). Equal amounts of total RNA $(10-15 \mu \mathrm{g} / \mathrm{lane})$ were denatured $\left(65^{\circ} \mathrm{C}\right.$, $5 \mathrm{~min}$ ) and loaded on a $1 \%$ agarose gel containing $0.2 \%$ formaldehyde solution and $0.5 \mu \mathrm{g} / \mathrm{ml}$ ethidium bromide. Electrophoresis was carried out in $20 \mathrm{mM}$ EDTA, Mops, $\mathrm{pH}$ 6.8, $5 \mathrm{mM}$ sodium acetate, and $1 \mathrm{mM}$ EDTA at $10 \mathrm{vol} / \mathrm{cm}^{2}$. RNA was transferred to a nitrocellulose membrane by vacuum blotting, and was then cross-linked under UV light (Gene linker; Bio-Rad). Filters were hybridized with a ${ }^{32} \mathrm{P}$ labeled full-length mouse pp60-srrc or mTNF cDNA. Labeling was performed with the Random Primed DNA Labeled Kit (Boehringer Mannheim, Mannheim, Germany). After hybridization overnight at $42^{\circ} \mathrm{C}$, the membrane was washed twice in $2 \times$ SSPE $-0.1 \%$ SDS at RT, twice in $0.1 \times$ SSPE$-0.1 \%$ SDS at RT, and exposed at the $-80^{\circ} \mathrm{C}$ for autoradiography. Before transfer, each gel was photographed, and the ethidium bromide-stained band at $18 \mathrm{~S}$ was examined to confirm equal RNA loading.

Histochemistry. Generated osteoclasts and histological sections of EDTA decalcified bone were stained for tartrate-resistant acid phosphatase (TRAP) activity using a commercial kit (Sigma Chemical Co.).

\section{Results}

C-src is specifically expressed by BMMs during osteoclastogenesis. To determine if c-src expression is specific to osteoclast differentiation, BMMs were cultured in the presence (osteoclastogenic culture) or absence (nonosteoclastogenic culture) of the murine marrow stromal line, ST2 (12). All cultures were collagenase-treated with time to remove ST2 cells (13). Northern analysis, using a full-length murine c-src cDNA, was then performed on RNA harvested from the remaining cells, which were TRAP-positive BMMs and osteoclasts in osteoclastogenic cultures, or TRAP-negative BMMs in nonosteoclastogenic cultures. As seen in Fig. $1 A$, BMMs, as they assume the osteoclast phenotype, contain increasing amounts of c-src mRNA. The protooncogene message is meaningfully expressed by BMMs after $5 \mathrm{~d}$ in only osteoclastogenic culture, but not in the absence of ST2 cells. Immunoblot analysis indicates that c-src protein induction in BMMs also progressively increases exclusively in osteoclastogenic culture (Fig $1 B$ ).

To confirm that the increase in c-src in osteoclastogenic culture reflects the macrophage, and not stromal population, ST2 cells were plated alone at the same density as in coculture. After $3 \mathrm{~d}$, some plates were treated with collagenase to lift the ST2 cells. Nonlifted and lifted ST2 cells, as well as any remaining on the plate after collagenase exposure, were lysed, and the lysates were assayed by immunoblot for c-src content. While nonlifted (i.e., total) and lifted ST2 cells contain abundant c-src protein, the number of ST2 cells remaining on the plate after collagenase treatment is insufficient to yield a signal (Fig. 1C). Thus, c-src detectable in osteoclastogenic culture after collagenase lifting of ST2 cells represents only the c-src present in the macrophage and osteoclast populations.

Finally, we asked if ST2 cell induction of BMM c-src is specific to stromal cells capable of promoting osteoclastogenesis. To this end, we turned to mouse $3 \mathrm{~T} 3$ fibroblasts, which are incapable of inducing BMMs to express the osteoclast phenotype (data not shown). Mirroring the conditions of ST2 cell/ macrophage coculture, BMMs and 3T3 cells were maintained in the presence of $1,25(\mathrm{OH})_{2} \mathrm{D}_{3}$ and dexamethasone. In contrast to ST2-containing cocultures wherein c-src is abundant, the protooncogene is not meaningfully expressed under the aegis of nonosteoclastogenic 3T3 cells (Fig. $1 D$ ).

LPS induces c-src expression by BMMs. Because LPS is known to be resorptive in bone organ culture $(15,16)$, we asked if the molecule prompts BMMs, in nonosteoclastogenic conditions, to express the osteoclast specific marker, c-src. En- 


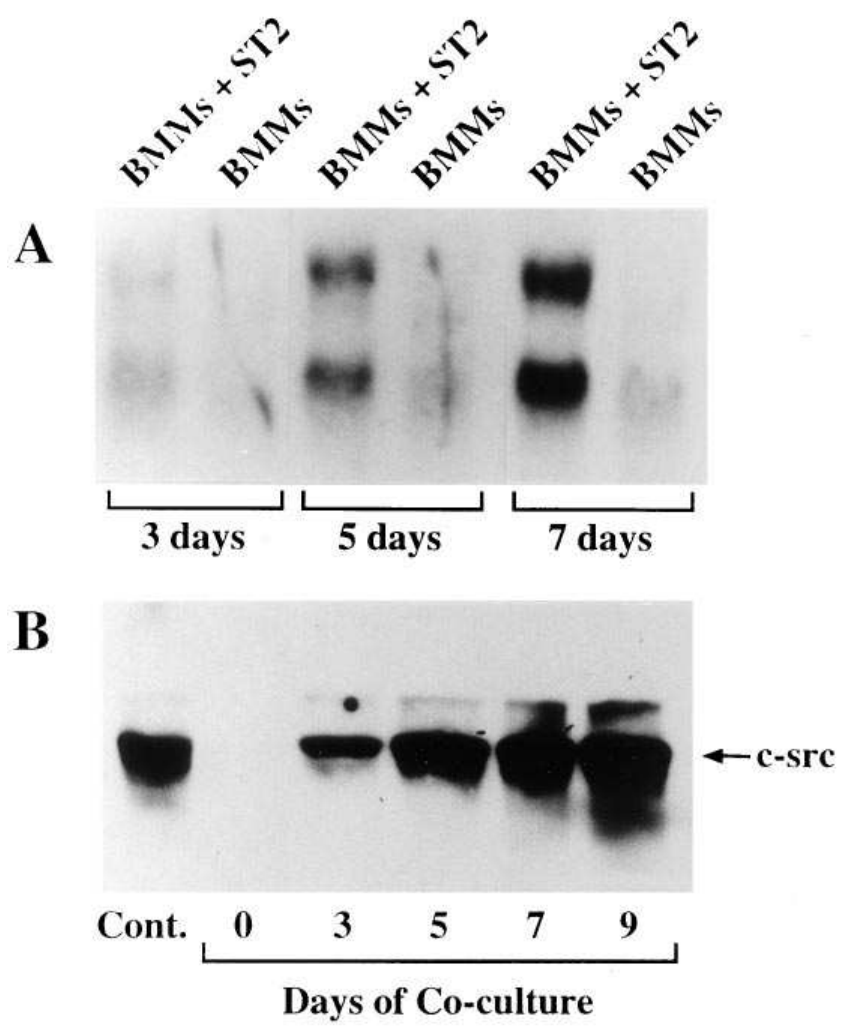

C

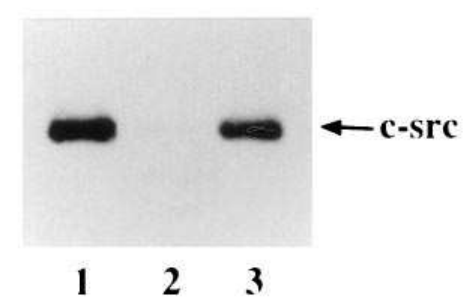

D

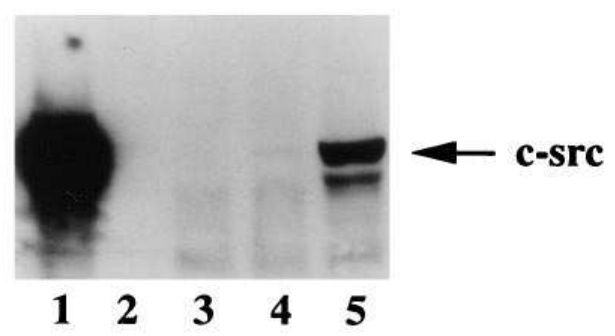

Figure 1. C-src is specifically expressed by marrow macrophages undergoing osteoclastogenesis. (A) BMMs were cultured alone, or to generate osteoclasts, with ST2 cells and steroids. ST2 cells were removed by collagenase treatment over time. RNA isolated from residual cells was subjected to Northern analysis with a c-src cDNA. $(B)$ BMMs were cultured for $7 \mathrm{~d}$ in the absence (0), or over time, in the presence of ST2 cells. All plates were collagenase-treated, and detached cells were removed. The remaining cells were lysed, and c-src content of equal amounts of lysate was determined by immunoblot. (C) ST2 cells were plated alone at the same density used in osteoclastogenic coculture. After $3 \mathrm{~d}$, the plate was collagenase-treated. Detached (lane 1) and any residual ST2 cells (lane 2) were lysed separately, as were fresh ST2 cells in numbers equal to those recovered from the dish (lane 3). The c-src content of each lysate was determined by immunoblot. $(D)$ BMMs were cultured alone (lane 3 ) or with either osteoclastogenic ST2 (lane 1) or nonosteoclastogenic 3T3

\section{c-src- - ese

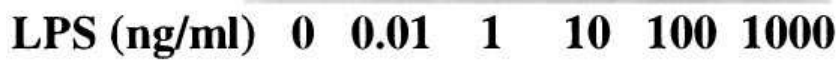

Figure 2. LPS induces c-src expression by BMMs. BMMs, cultured for $3 \mathrm{~d}$, were exposed to increasing concentrations of LPS. After $24 \mathrm{~h}$, equal amounts of cell lysates were analyzed by immunoblot for c-src content.

dotoxin, at concentrations as low as $10 \mathrm{pg} / \mathrm{ml}$, dose-dependently stimulates c-src protein expression by BMMs cultured in the absence of ST2 cells (Fig. 2).

TNF induces c-src expression by BMMs. To identify possible humoral mediators of LPS-stimulated c-src expression, BMMs, in the absence of ST2 cells, were treated for $18 \mathrm{~h}$ with a broad range of hematopoietic cytokines, including those known to impact osteoclast recruitment. As seen in Fig. 3, of the many cytokines tested, only TNF dramatically enhances c-src protein expression. The c-src-inductive effect of TNF appears at concentrations as low as $0.5 \mathrm{ng} / \mathrm{ml}$ and maximizes at $20 \mathrm{ng} / \mathrm{ml}$ (Fig. $4 A$ ). TNF-induced c-src mRNA (Fig. $4 B$ ) and protein (Fig. $4 C$ ) appear within 2-3 h of cytokine exposure. Message levels optimize by $6 \mathrm{~h}$, whereas c-src protein increases for at least $3 \mathrm{~d}$.

TNF stimulates BMM c-src expression exclusively via the 55-kD TNFr. The murine p55TNFr recognizes both murine and human TNF, while the p75TNFr binds only the murine species (17). As seen in Fig. $5 A$, both murine (lane 3) and human (lane 4) TNF induce c-src protein, indicating that at least the p55TNFr mediates this event. To further delineate the TNFr-signaling c-src induction, we took advantage of mice in which the p55TNFr, p75TNFr, or both had been deleted. As expected, BMMs lacking both TNFrs fail to respond to the cytokine (Fig. 5 B). Most importantly, while TNF-induced c-src expression is unaffected in BMMs derived from the p75TNFr knockout animals, the response is lost in cells in which p55TNFr is absent.

LPS sequentially induces TNF and c-src proteins in vitro. Both LPS (Fig. 2) and TNF (Figs. 3 and 4) enhance osteoclast precursor c-src content, and endotoxin is known to induce TNF (18-20). To explore the possibility that TNF mediates the LPS-inductive effect on c-src, we first asked if endotoxinexposed cells sequentially express the cytokine and protooncogene. Thus, BMMs cultured in nonosteoclastogenic conditions were LPS-treated for as long as $16 \mathrm{~h}$. The cells were lysed, and total lysate was immunoblotted with both anti-TNF and anti-c-src antibodies. Fig. 6 shows that expression of both proteins is LPS-enhanced, but with an interesting temporal

(lane 4) cells. After $7 \mathrm{~d}$ the stromal cells were removed, the remaining cells were lysed, and lysate c-src content was determined by immunoblot. Lane 2 represents loading sample buffer, and lane 5 represents c-src-enriched preparation of platelets (positive control). 


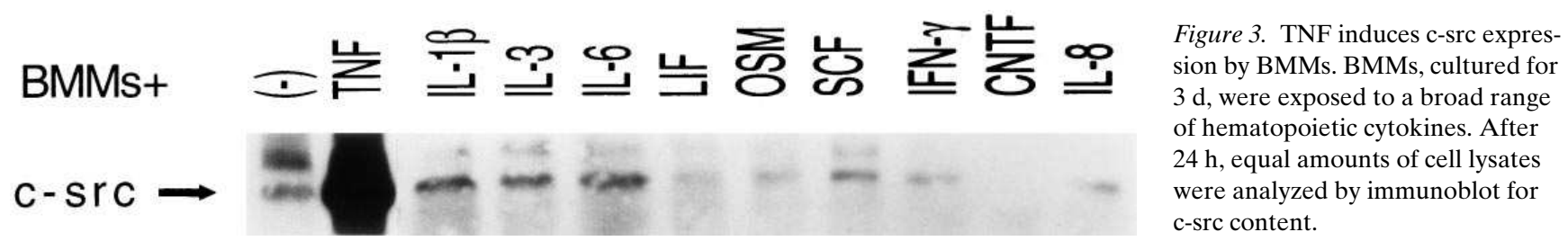

asynchrony. TNF appears within $30 \mathrm{~min}$, and disappears by $8 \mathrm{~h}$. $\mathrm{C}$-src is a later emerging moiety. The protooncogene begins to increase after $4 \mathrm{~h}$ of LPS exposure, and remains elevated at $16 \mathrm{~h}$. The TNF doublet represents intact cytokine, and probably LPS-induced cleavage product.
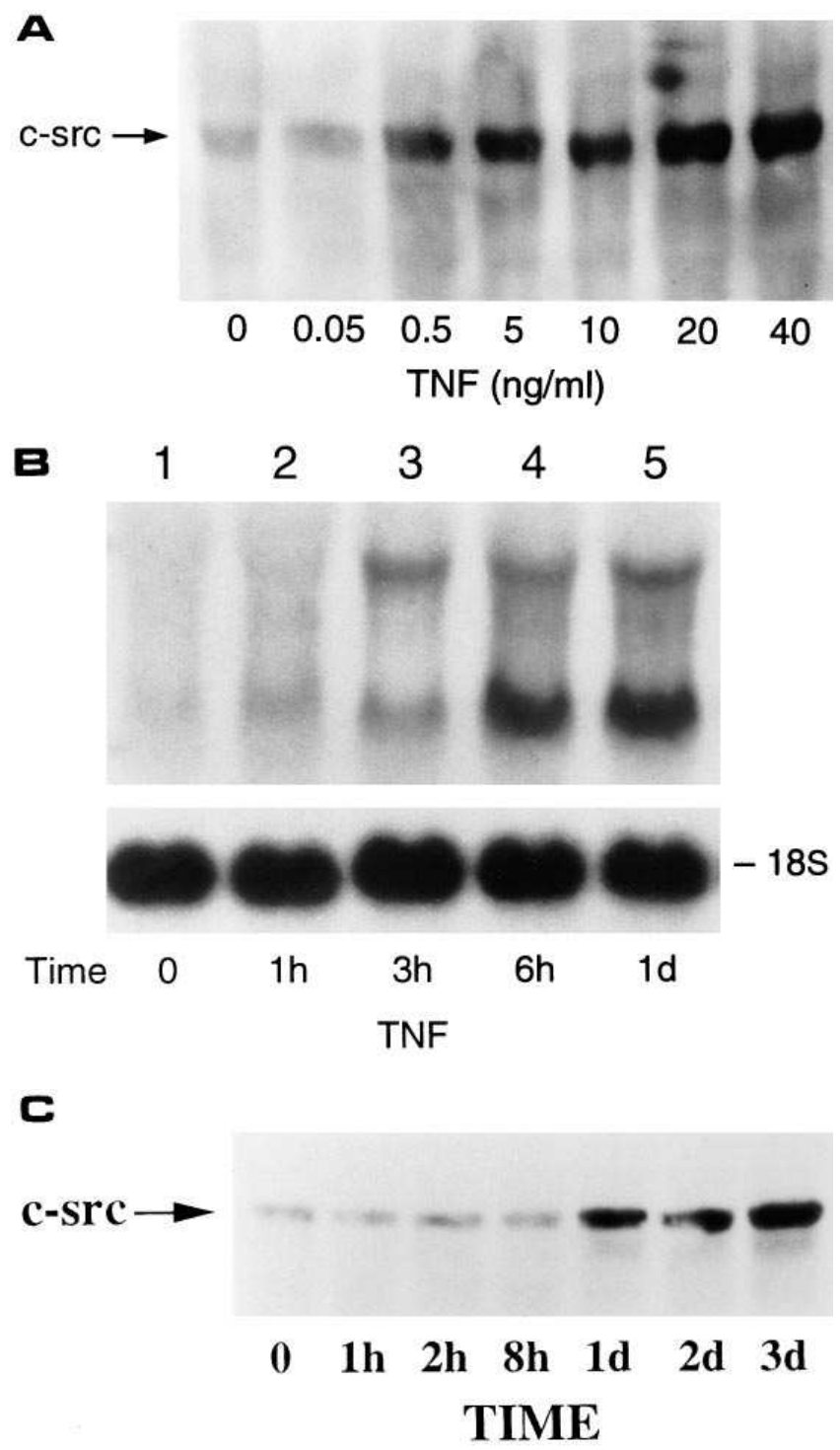

Figure 4. TNF induction of c-src is concentration- and time-dependent. (A) BMMs were incubated for $24 \mathrm{~h}$ with increasing concentrations of TNF (specific activity, $1.1 \times 10^{8} \mathrm{U} / \mathrm{mg}$ ). Equal amounts of cell lysates were immunoblotted with anti-c-src mAb. BMMs were incubated without (0), or with TNF (10 ng/ml). RNA was extracted with time, and was probed with c-src cDNA $(B)$, or equal amounts of protein from total cell lysates were extracted with time, and immunoblotted with anti-c-src antibody $(C)$.
LPS induces TNF and c-src in vivo and ex vivo. To extend our in vitro observations to the in vivo state, we asked if BMMs derived from LPS-treated animals express increased c-src. In fact, the quantity of c-src and TNF contained within cells, cultured ex vivo for $24 \mathrm{~h}$, is directly related to duration of LPS exposure in vivo, and, to some degree, to the circulating levels of cytokine achieved (Fig. 7).

Thalidomide and anti-TNF antibody blocks LPS-induced $c$-src. The time course of the appearance of the two proteins is consistent with TNF-mediating LPS induction of c-src (Fig. 6). To test this hypothesis, we determined if TNF-blocking agents ablate the c-src-enhancing effect of endotoxin. We first established that the antiinflammatory drug thalidomide, which specifically dampens TNF synthesis by accelerating degradation
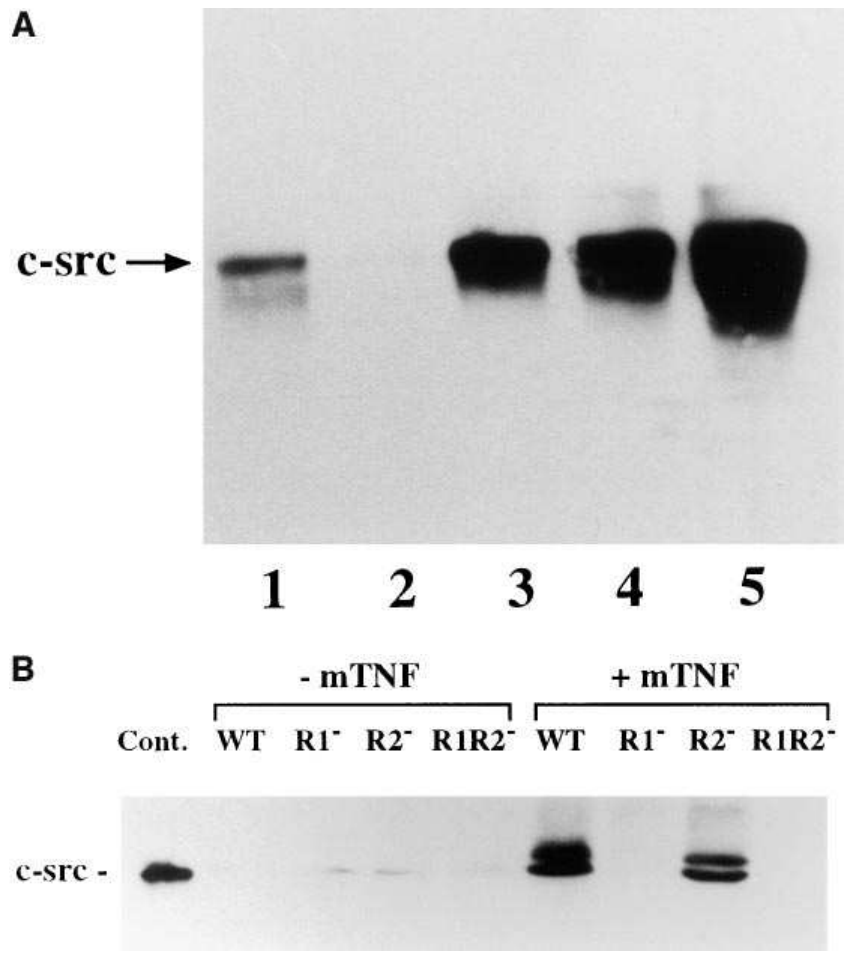

Figure 5. TNF induces c-src via the p55 TNFr. $(A)$ BMMs were exposed to carrier (lane 2$)$ or murine $(10 \mathrm{ng} / \mathrm{ml}$; lane 3 ) or human TNF $(2 \mathrm{ng} / \mathrm{ml}$; lane 4$)$ for $18 \mathrm{~h}$. The cells were lysed, and the amounts of c-src in equal amounts of lysate protein were determined by immunoblot. Lanes 1 and 5 represent c-src positive control and c-src from osteoclast total lysate, respectively. $(B)$ BMMs were isolated from wildtype $(W T)$ mice, and from those for which the $\mathrm{p} 55(\mathrm{R} 1-)$ or $\mathrm{p} 75$ (R2-) TNFr or both (R1R2-) had been deleted. The cells were exposed to carrier or TNF $(10 \mathrm{ng} / \mathrm{ml})$ for $18 \mathrm{~h}$, lysed, and the amounts of c-src were determined by immunoblot in equal amounts of lysate protein. Cont. represents c-src-enriched preparation of platelets, as positive control. 


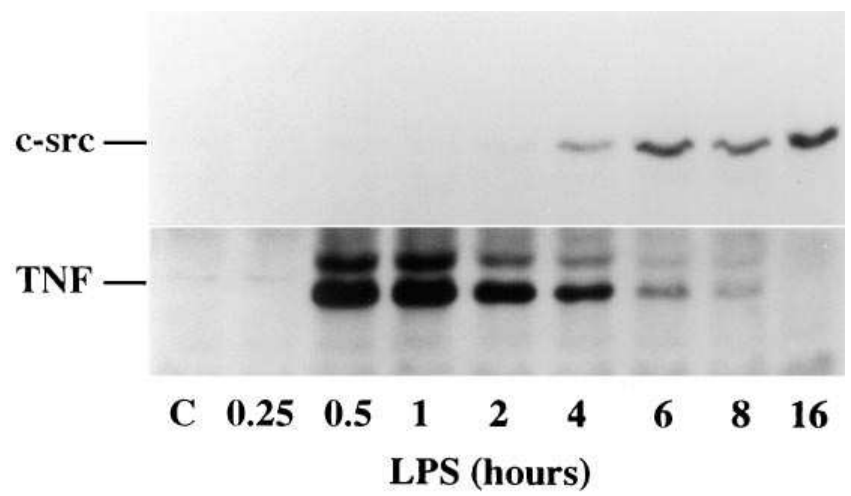

Figure 6. LPS sequentially induces TNF and c-src proteins in vitro. BMMs were treated with LPS $(100 \mathrm{ng} / \mathrm{ml})$. The cells were lysed over time, and total lysates were electrophoresed. The top half of the gel was probed with anti-c-src mAb, and the bottom half with antiTNF Ab.

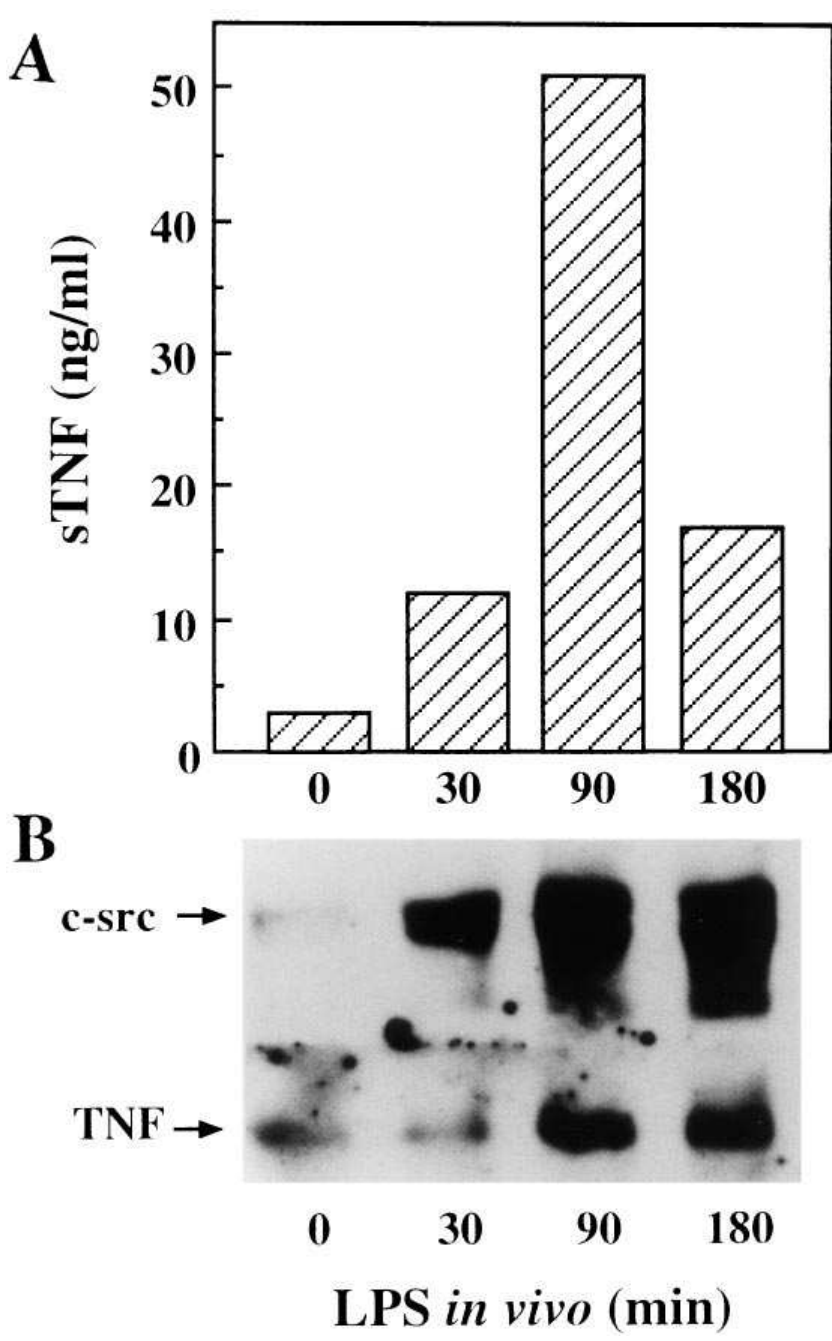

Figure 7. In vivo administration of LPS induces c-src. Mice were injected with LPS $(20 \mathrm{mg} / \mathrm{kg}$ body weight $)$ and killed, over time. TNF in serum $(s T N F)$ collected at death was measured by ELISA $(A)$. BMMs from control (0) and LPS-treated mice were cultured for $24 \mathrm{~h}$, lysed, and total lysate was immunoblotted for TNF and c-src content $(B)$.

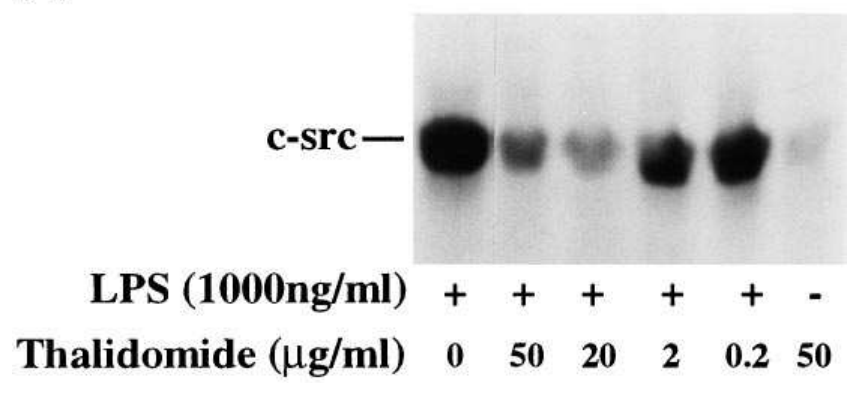

B

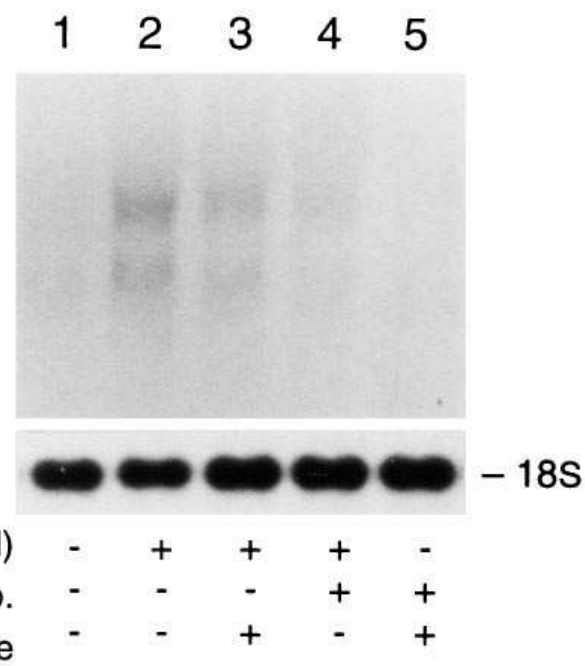

Figure 8 . Thalidomide and anti-TNF antibody block LPS induced c-src. (A) BMMs were treated with LPS in the presence of increasing concentrations of thalidomide. After $24 \mathrm{~h}$ total cell lysates were analyzed by immunoblot, for c-src content. (B) BMMs were maintained without (-) or with (+) LPS, anti-TNF antibody $(m c A b)(10 \mu \mathrm{g} / \mathrm{ml})$ and/or thalidomide $(20 \mu \mathrm{g} / \mathrm{ml})$ for $24 \mathrm{~h}$. RNA was extracted and probed with a c-src cDNA.

of its mRNA (21), dose-dependently blunts endotoxin's impact on c-src expression (Fig. $8 A$ ). BMM viability is not influenced by the drug (data not shown). Confirming that the cytokine mediates endotoxin's effect, LPS-induced c-src mRNA is profoundly reduced by anti-TNF antibody, and approximates levels in virgin BMMs when the cells are exposed to both antibody and thalidomide (Fig. $8 B$ ).

LPS induces osteoclastogenesis in vivo via the p55TNFr. The data presented thus far, establishing that LPS induces BMM c-src via TNF, is consistent with, but does not prove, the proposition that LPS-stimulated osteoclastogenesis is mediated through the cytokine. To address this issue, we administered endotoxin to wild-type mice and those lacking the p55TNFr, the species we confirmed mediates TNF induction of c-src (Fig. 5). Marrow obtained with time was cultured for $7 \mathrm{~d}$ with the osteoclastogenic steroids $1,25(\mathrm{OH})_{2} \mathrm{D}_{3}$ and dexamethasone. As seen in Fig. 9 A, the magnitude of ex vivo osteoclastogenesis, manifest by generation of TRAP-expressing cells, is directly related in wild-type marrow culture, to the duration of LPS exposure in vivo. In contrast, no LPS inductive effect occurs in marrow cultures containing p55TNFr-deleted 


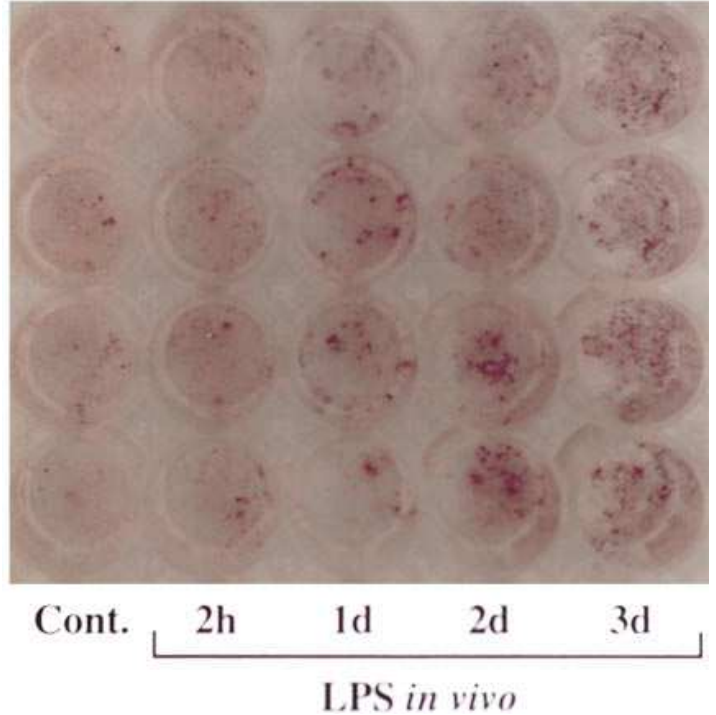

Figure 9. LPS administration to wild-type, but not p55 TNFrdeleted mice, enhances osteoclastogenesis, ex vivo. Wild-type ( $A$ and $B)$ or p55 TNFr-deleted $(B)$ mice were injected with LPS $(20 \mathrm{mg} / \mathrm{kg}$ body wt.) and killed at the indicated times. Marrow cultured for $7 \mathrm{~d}$ in the presence of $1 \mathrm{nM} 1,25(\mathrm{OH})_{2} \mathrm{D}_{3}$ and $100 \mathrm{nM}$ dexamethasone was fixed and stained for TRAP activity. Stain reflects intensity increasing numbers of TRAP-expressing cells. marrow (Fig. 9 B). We also find that for reasons unknown, basal osteoclastogenesis is consistently less in cultures of marrow derived from mutant than from wild-type animals (Fig. 9B).

Our observations that LPS induces c-src and ex vivo osteoclastogenesis through the p55TNFr suggests that endotoxin treatment of wild-type mice, but not those lacking the TNF receptor, will prompt osteoclastogenesis. Consonant with this hypothesis, histological sections of bone contain abundant marrow-residing, TRAP-expressing cells in LPS-exposed wildtype animals (Fig. $10 \mathrm{~B}$ ). TRAP-containing cells are, in con-
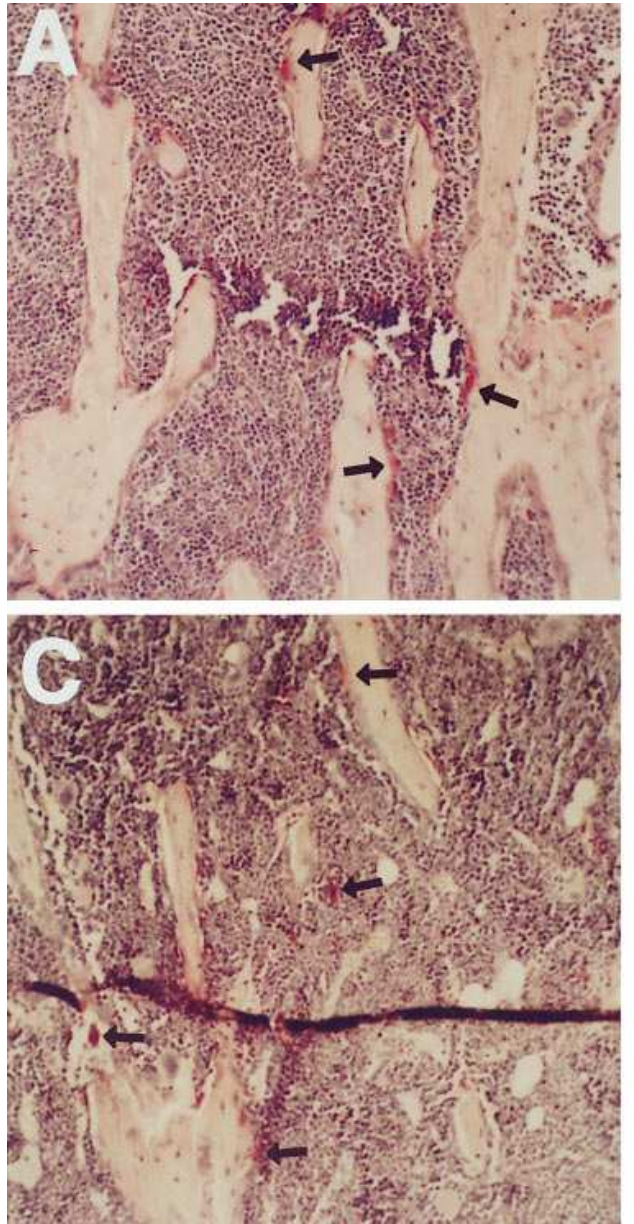
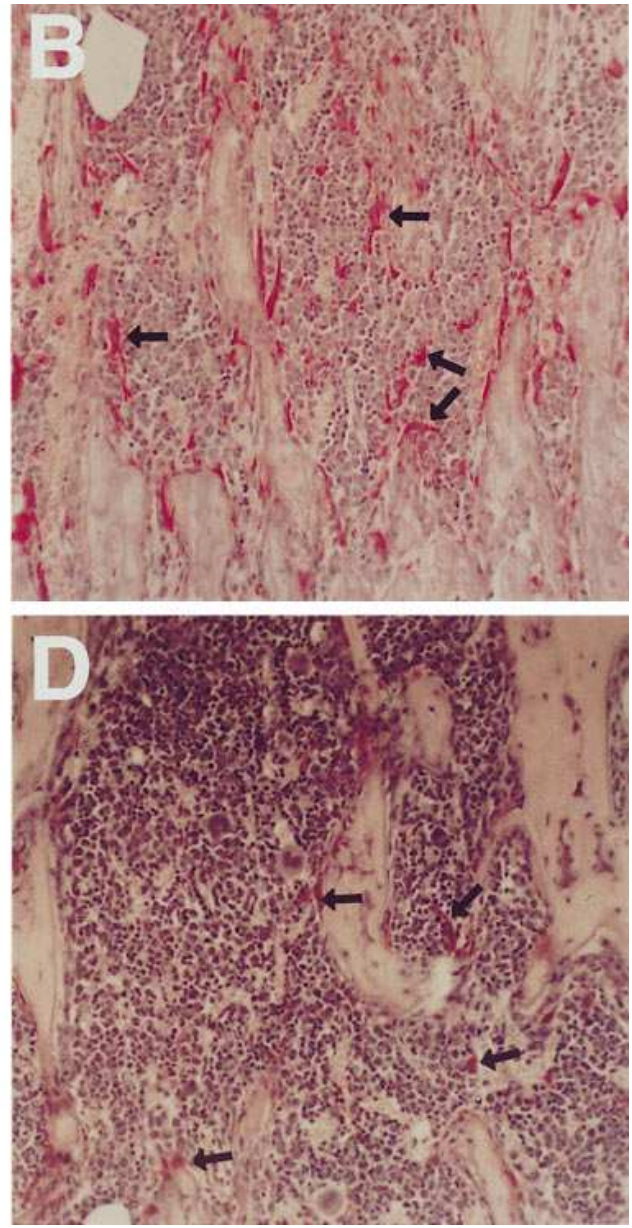

Figure 10. LPS administration to wild-type, but not p55 TNFrdeleted mice enhances osteoclastogenesis, in vivo. Wild-type $(A$ and $B$ ) or p55 TNFr-deleted ( $C$ and $D)$ mice, injected with carrier $(A$ and $C)$ or LPS (20 mg/kg body wt) (B and $D$ ), were killed after $48 \mathrm{~h}$. Histological sections of the proximal tibiae were stained for TRAP activity. Red staining cells (arrows) are osteoclasts and their immediate precursors. 
trast, much fewer in untreated wild-type mice, wherein all those present are juxtaposed to bone, and not marrow-occupying cells (Fig. $10 \mathrm{~A}$ ). Similar to osteoclasts generated in vitro under the influence of TNF (data not shown), those present in LPS-treated mice are substantially larger than the control. The dramatic increase in osteoclast number occurring in wild-type mice after LPS-treatment does not, however, occur in those absent the p55TNFr (Fig. $10 \mathrm{D}$ ).

\section{Discussion}

Systemic skeletal disorders, particularly osteoporosis, have received great attention, and hence it is generally not appreciated that the most prevalent forms of osteopenia are those due to bacterial infection, especially periodontal disease (2). Because offending bacteria do not reside in alveolar bone, per se, it is their products and not the intact microorganisms that prompt the resorptive process (2).

LPS, a cell wall component of gram-negative bacteria (22), is abundant in sites of periodontitis, and its capacity to stimulate resorption of bone organ culture (6) provides strong evidence that endotoxin is central to alveolar bone loss. On the other hand, the means by which LPS prompts resorption in vitro, and most importantly, whether the molecule is osteoclastogenic in vivo, have not been determined until this study.

The osteoclast is a polykaryon of hematopoietic origin, and a member of the monocyte/macrophage family (23). Furthermore, its recruitment is influenced by macrophage-produced proinflammatory cytokines such as TNF, interleukin-1 and -6, and GM-CSF, as well as prostaglandins of the E series (24-29). Thus, mononuclear phagocytes serve as both osteoclast precursors and paracrine promoters of the osteoclast phenotype.

Model development whereby osteoclasts can be generated in culture has added substantially to the information regarding the mechanisms of osteoclastogenesis. These models typically contain osteoclast precursors, namely monocytes/macrophages, and accessory cells in the form of stromal cells or osteoblasts $(12,13)$. While contact between accessory cells and osteoclast precursors is essential to murine osteoclastogenesis $(12,13)$, stromal cells also secrete soluble, as yet ill-defined, osteoclastogenic molecules (27). Therefore, exogenously added agents may exert their osteoclastogenic effect directly by targeting osteoclast precursors, or indirectly via intermediary cells of stromal origin. Thus, our first aim was to determine if LPS directly or indirectly prompts osteoclast precursor differentiation. We reasoned that induction of an osteoclast-specific marker in a pure population of BMMs, maintained in nonosteoclastogenic conditions, would indicate that endotoxin promotes bone resorption by directly targeting osteoclast precursors.

$\mathrm{C}$-src is a protooncogene essential to osteoclast function $(30,31)$. In fact, deletion of the c-src gene prompts, as its unique phenotype, osteopetrosis (32), the family of sclerotic bone diseases emblematic of osteoclast dysfunction $(32,33)$. While total culture c-src content is known to parallel osteoclast formation (31), experiments documenting this phenomenon failed to discern which cell type, in osteoclastogenic cultures, progressively express the protooncogene. This fact is of particular importance as stromal cells are rich in c-src (Fig. 1). We document that the differentiating osteoclast precursor is the source of enhanced c-src expressed during differentiation of the resorptive polykaryon, and, most importantly, c-src content is not increased in the same BMMs placed in nonosteo- clastogenic conditions. Thus, c-src is a specific marker of the osteoclast phenotype. The fact that pure populations of BMMs cultured in nonosteoclastogenic conditions express abundant c-src when exposed to LPS suggests that the osteoclast-differentiating effect of endotoxin is mediated by direct interaction of this molecule with osteoclast precursors.

LPS prompts expression by macrophages of a host of cytokines $(19,20,34)$. Thus, we postulated that the bacterial product's c-src-promoting properties may reflect an autocrine/ paracrine phenomenon involving secretion of an intermediary molecule(s) which in turn induces the protooncogene in the same cell population. Of a number of cytokines examined, including those that are bone-resorptive and LPS-induced, only TNF substantially enhances c-src expression, and does so by transactivating the c-src gene (data not shown).

Many cells, including macrophages, express two TNFrs (35). While the type I or p55TNFr has been viewed as the major, biologically active form, recent evidence indicates the type II or p75TNFr is also functional (35-42). For example, while p75TNFr mediates differentiation of early hematopoietic precursors, p55TNFr is active in later stages of the process (43). Furthermore, soluble TNF targets primarily, if not exclusively, p55TNFr, but membrane-residing TNF activates both receptors (37). Thus, we asked which TNFr transmits the cytokine's c-src induction.

Our first experiments in this regard took advantage of the capacity of the murine p55TNFr to recognize both the murine and human cytokine, while the larger receptor binds only the murine ligand (17). The fact that both species of TNF induce BMM c-src indicated that at least the p55TNFr is involved in this event. As cells derived from mice lacking this receptor, but not the p75TNFr, fail to express c-src in response to the cytokine, the smaller receptor must exclusively transmit the c-src inductive signal.

Because LPS induces both TNF and c-src in vitro and in vivo, and the cytokine in turn amplifies expression of the protooncogene, we explored the possibility that LPS enhancement of c-src is mediated via TNF. In fact, the sequence of the appearance of TNF and c-src, in LPS-exposed BMMs, is consistent with this hypothesis. Most importantly, anti-TNF antibody dampens LPS induction of c-src, establishing that the cytokine is an autocrine/paracrine factor mediating endotoxin's effect. Interestingly, LPS induces c-src more rapidly than does exogenously added TNF (compare Figs. 4 and 6). While the reason for this seeming discrepancy is unknown, it may relate to higher ambient concentrations of the cytokine in LPStreated cells and induction of membrane TNF, which is also known to exert important biological effects (37).

Thalidomide is an antiinflammatory drug that specifically blocks TNF expression by accelerating decay of its mRNA (21). It is because of its anti-TNF properties that the drug is presently being administered to HIV-infected patients (44). The fact that thalidomide, like anti-TNF antibody, blocks LPSinduced c-src expression, is in keeping with the intermediary role played by the cytokine, and suggests that the drug, or an analogue, may be effective in preventing the osteolysis of chronic infection.

LPS is known to stimulate bone resorption in vitro (16), but its osteoclastogenic effect in vivo has never been directly established. The observation that LPS, administered to mice, induces BMM c-src pari passu with TNF, suggests that the bacterial product prompts osteoclast commitment in the intact 
animal. In fact, injected LPS rapidly induces osteoclast precursor differentiation, as assessed by osteoclastogenesis in marrow cultured, ex vivo, or histological examination of bone. The dramatic increase in osteoclast number appearing within 1-2 d of LPS administration is consistent with an attendant rapid induction of circulating TNF. Most importantly, this striking osteoclastogenic response does not appear in mice lacking the p55TNFr, establishing that LPS-induced osteoclastogenesis is mediated by TNF through its type I receptor. Thus, bone loss attending chronic infection is potentially arrested by agents targeting LPS-induced TNF or its p55 receptor.

\section{Acknowledgments}

We would like to thank Dr. Robert Schreiber for helpful discussions.

This study was supported in part by National Institutes of Health grant nos. DE05413 and AR32788 (S.L. Teitelbaum), AR42404 (F.P. Ross), the Barnes-Jewish Hospital Foundation (Y. Abu-Amer) and a grant from the Shriners Hospital for Crippled Children, St. Louis Unit (S.L. Teitelbaum)

\section{References}

1. Baroukh, B., and J.L. Saffar. 1991. Identification of osteoclasts and their mononuclear precursors. A comparative histological and histochemical study in hamster periodontitis. J. Periodontal Res. 26:161-166.

2. Nair, S.P., S. Meghji, M. Wilson, K. Reddi, P. White, and B. Henderson. 1996. Bacterially induced bone destruction: mechanisms and misconceptions. Infect. Immun. 64:2371-2380.

3. Lannigan, F.J., P. O'Higgins, and P. McPhie. 1993. The cellular mechanism of ossicular erosion in chronic suppurative otitis media. J. Laryngol. Otol. 107:12-16.

4. Holt, S.C., and J.L. Ebersole. 1991. The surface of selected periodontopathic bacteria: Possible role in virulence. In Periodontal Disease: Pathogens \& Host Immune Responses. S. Hamada, S.C. Holt, and J.R. McGhee, editors. Quintessence Publishing Co., Ltd. Tokyo. 79-98.

5. Iino, Y., and R.M. Hopps. 1984. The bone-resorbing activities in tissue culture of lipopolysaccharides from the bacteria Actinobacillus actinomycetemcomitans, Bacteroides gingivalis and Capnocytophaga ochracea isolated from human mouths. Arch. Oral Biol. 29:59-63.

6. Hausmann, E., L.G. Raisz, and W.A. Miller. 1970. Endotoxin: stimulation of bone resorption in tissue culture. Science (Wash. DC). 168:862-864.

7. Lipsich, L.A., A.J. Lewis, and J.S. Brugge. 1983. Isolation of monoclonal antibodies that recognize the transforming proteins of avian sarcoma viruses. $J$. Virol. 48:352-360.

8. Rothe, J., W. Lesslauer, H. Lotscher, Y. Lang, P. Koebel, F. Kontgen, A. Althage, R. Zinkernagel, M. Steinmetz, and H. Bluethmann. 1993. Mice lacking the tumour necrosis factor receptor 1 are resistant to TNF-mediated toxicity but highly susceptible to infection by Listeria monocytogenes. Nature (Lond.). 364:798-800.

9. Erickson, S.L., F.J. de Sauvage, K. Kikly, K. Carver-Moore, S. PittsMeek, N. Gillett, K.C. Sheehan, R.D. Schreiber, D.V. Goeddel, and M.W. Moore. 1994. Decreased sensitivity to tumour-necrosis factor but normal T-cell development in TNF receptor-2-deficient mice. Nature (Lond.). 372:560-563.

10. Clohisy, D.R., J.C. Chappel, and S.L. Teitelbaum. 1989. Bone marrowderived mononuclear phagocytes autoregulate mannose receptor expression. $J$. Biol. Chem. 264:5370-5377.

11. Kitazawa, R., R.B. Kimble, J.L. Vannice, V.T. Kung, and R. Pacifici. 1994. Interleukin-1 receptor antagonist and tumor necrosis factor binding protein decrease osteoclast formation and bone resorption in ovariectomized mice. J. Clin. Invest. 94:2397-2406.

12. Udagawa, N., N. Takahashi, T. Akatsu, T. Sasaki, A. Yamaguchi, H. Kodama, T.J. Martin, and T. Suda. 1989. The bone marrow-derived stromal cell lines MC3T3-G2/PA6 and ST2 support osteoclast-like cell differentiation in cocultures with mouse spleen cells. Endocrinology. 125:1805-1813.

13. Shioi, A., F.P. Ross, and S.L. Teitelbaum. 1994. Enrichment of generated murine osteoclasts. Calcif. Tissue Int. 55:387-394.

14. Laemmli, U.K. 1970. Cleavage of structural proteins during the assembly of the head of bacteriophage T4. Nature (Lond.). 227:680-685.

15. Carson, R.E., F.S. Sayegh, and P.F. Fedi, Jr. 1978. Osteoclastic resorption of alveolar bone affected by periodontitis - correlation of light microscopic and scanning electron microscopic observations. J. Periodontol. 49:406-414.

16. Shuto, T., E. Jimi, T. Kukita, M. Hirata, and T. Koga. 1994. Granulo- cyte-macrophage colony stimulating factor suppresses lipopolysaccharideinduced osteoclast-like cell formation in mouse bone marrow cultures. Endocrinology. 134:831-837.

17. Lewis, M., L.A. Tartaglia, A. Lee, G.L. Bennett, G.C. Rice, G.H. Wong, E.Y. Chen, and D.V. Goeddel. 1991. Cloning and expression of cDNAs for two distinct murine tumor necrosis factor receptors demonstrate one receptor is species specific. Proc. Natl. Acad. Sci. USA. 88:2830-2834.

18. Abu-Amer, Y., and Z. Bar-Shavit. 1994. Regulation of TNF- $\alpha$ release from bone marrow-derived macrophages by vitamin D. J. Cell. Biochem. 55: $435-444$.

19. Beutler, B., N. Krochin, I.W. Milsark, C. Luedke, and A. Cerami. 1986. Control of cachectin (tumor necrosis factor) synthesis: mechanisms of endotoxin resistance. Science (Wash. DC). 232:977-980.

20. Han, J., T. Brown, and B. Beutler. 1990. Endotoxin-responsive sequences control cachectin/tumor necrosis factor biosynthesis at the translational level. J. Exp. Med. 171:465-475.

21. Moreira, A.L., E.P. Sampaio, A. Zmuidzinas, P. Frindt, K.A. Smith, and G. Kaplan. 1993. Thalidomide exerts its inhibitory action on tumor necrosis factor $\alpha$ by enhancing mRNA degradation. J. Exp. Med. 177:1675-1680. 54-61.

22. Rietschel, E.T., and H. Brade. 1992. Bacterial endotoxins. Sci. Am. 267

23. Teitelbaum, S.L., Y. Abu-Amer, and F.P. Ross. 1995. Molecular mechanisms of bone resorption. J. Cell. Biochem. 59:1-10.

24. Mundy, G.R. 1993. Role of cytokines in bone resorption. J. Cell. Biochem. 53:296-300.

25. Pfeilschifter, J., C. Chenu, A. Bird, G.R. Mundy, and G.D. Roodman. 1989. Interleukin-1 and tumor necrosis factor stimulate the formation of human osteoclast-like cells in vitro. J. Bone Miner. Res. 4:113-118.

26. Passeri, G., G. Girasole, S.C. Manolagas, and R.L. Jilka. 1994. Endogenous production of tumor necrosis factor by primary cultures of murine calvarial cells: influence on IL-6 production and osteoclast development. Bone Miner. 24:109-126.

27. Suda, T., N. Udagawa, I. Nakamura, C. Miyaura, and N. Takahashi. 1996. Modulation of osteoclast differentiation by local factors. Bone. 17:8791.

28. Kaji, H., T. Sugimoto, M. Kanatani, M. Fukase, M. Kumegawa, and K. Chihara. 1996. Prostaglandin E2 stimulates osteoclast-like cell formation and bone-resorbing activity via osteoblasts: role of cAMP-dependent protein kinase. J. Bone Miner. Res. 11:62-71.

29. Perkins, S.L., R. Gibbons, S. Kling, and A.J. Kahn. 1994. Age-related bone loss in mice is associated with an increased osteoclast progenitor pool. Bone. 15:65-72.

30. Horne, W.C., L. Neff, D. Chatterjee, A. Lomri, J.B. Levy, and R. Baron. 1992. Osteoclasts express high levels of $\mathrm{pp}^{\mathrm{C}^{\mathrm{c}-\mathrm{src}}}$ in association with intracellular membranes. J. Cell Biol. 119:1003-1013.

31. Tanaka, S., N. Takahashi, N. Udagawa, T. Sasaki, Y. Fukui, T. Kurokawa, and T. Suda. 1992. Osteoclasts express high levels of pp60 ${ }^{\text {c-src }}$, preferentially on ruffled border membranes. FEBS Lett. 313:85-89.

32. Soriano, P., C. Montgomery, R. Geske, and A. Bradley. 1991. Targeted disruption of the c-src proto-oncogene leads to osteopetrosis in mice. Cell. 64: 693-702.

33. Boyce, B.F., T. Yoneda, C. Lowe, P. Soriano, and G.R. Mundy. 1992 Requirement of pp60c-src expression for osteoclasts to form ruffled borders and resorb bone in mice. J. Clin. Invest. 90:1622-1627.

34. Sweet, M.J., and D.A. Hume. 1996. Endotoxin signal transduction in macrophages. J. Leukocyte Biol. 60:8-26.

35. Vandenabeele, P., W. Declercq, R. Beyaert, and W. Fiers. 1995. Two tumour necrosis factor receptors: structure and function. Trends Cell Biol. 5:392399.

36. Sheehan, K.C.F., J.K. Pinckard, C.D. Arthur, L.P. Dehner, D.V. Goeddel, and R.D. Schreiber. 1995. Monoclonal antibodies specific for murine p55 and p75 tumor necrosis factor receptors: identification of a novel in vivo role for p75. J. Exp. Med. 181:607-617.

37. Grell, M., E. Douni, H. Wajant, M. Lohden, M. Clauss, B. Maxeiner, S Georgopoulos, W. Lesslauer, G. Kollias, K. Pfizenmaier, and P. Scheurich. 1995. The transmembrane form of tumor necrosis factor is the prime activating ligand of the $80 \mathrm{kDa}$ tumor necrosis factor receptor. Cell. 83:793-802.

38. Wong, G.H., L.A. Tartaglia, M.S. Lee, and D.V. Goeddel. 1992. Antiviral activity of tumor necrosis factor is signaled through the 55-kDa type I TNF receptor [corrected] [published erratum: 1993. J. Immunol. 150(2):705]. J. Immunol. 149:3350-3353.

39. Brakebusch, C., Y. Nophar, O. Kemper, H. Engelmann, and D. Wallach. 1992. Cytoplasmic truncation of the p55 tumour necrosis factor (TNF) receptor abolishes signaling, but not induced shedding of the receptor. $E M B O$ J. 11:943-950.

40. Pfeffer, K., T. Matsuyama, T.M. Kundig, A. Wakeham, K. Kishihara, A. Shahinian, K. Wiegmann, P.S. Ohashi, M. Kronke, and T.W. Mak. 1993. Mice deficient for the $55 \mathrm{kd}$ tumor necrosis factor receptor are resistant to endotoxic shock, yet succumb to L. monocytogenes infection. Cell. 73:457-467.

41. Tartaglia, L.A., and D.V. Goeddel. 1992. Two TNF receptors. Immunol. Today. 13:151-153.

42. Tartaglia, L.A., D.V. Goeddel, C. Reynolds, I.S. Figari, R.F. Weber, 
B.M. Fendly, and M.A. Palladino, Jr. 1993. Stimulation of human T-cell proliferation by specific activation of the $75-\mathrm{kD}$ a tumor necrosis factor receptor. $J$. Immunol. 151:4637-4641.

43. Fahlman, C., F.W. Jacobsen, O.P. Veiby, I.K. McNiece, H.K. Blomhoff, and S.E. Jacobsen. 1994. Tumor necrosis factor-alpha (TNF-alpha) potently enhances in vitro macrophage production from primitive murine hematopoetic progenitor cells in combination with stem cell factor and interleukin-7: novel stimulatory role of p55 TNF receptors. Blood. 84:1528-1533.

44. Makonkawkeyoon, S., R.N.R. Limson-Pobre, A.L. Moreira, V. Schauf, and G. Kaplan. 1993. Thalidomide inhibits the replication of human immunodeficiency virus type 1. Proc. Natl. Acad. Sci. USA. 90:5974-5978. 